\title{
A ECONOMIA CONTINENTAL CHINESA E SEU EFEITO GRAVITACIONAL
}

\author{
Diego Pautasso
}

\section{RESUMO}

O presente artigo aborda o desenvolvimento nacional e a inserção internacional da China. O objetivo é discutir como a formação de uma economia continental na China tem se transformado num fator de projeção desse país no sistema internacional, analisando como a formação de uma economia continental produz uma espécie de efeito gravitacional favorecendo a formulação da estratégia internacional chinesa nesta conjuntura de transição sistêmica. O artigo desenvolve-se discutindo com análises recorrentes sobre o processo de desenvolvimento e de inserção da internacional da China. $O$ argumento central defendido no artigo é que o desenvolvimento da economia continental e a ampliação da capacidade econômica tornam-se um instrumento da política externa chinesa. Em outras palavras, a China tende a criar um forte efeito gravitacional em escala global e utilizar-se disso como parte de sua estratégia internacional. $O$ artigo organiza-se da seguinte forma: na primeira parte, discorremos sobre a evolução recente do desenvolvimento chinês, centrando foco nos desafios da formação de uma economia de dimensões continentais; na segunda, abordamos como o incremento da capacidade econômica chinesa implica num crescente efeito gravitacional do país em escala global; por fim, argumentamos que a diplomacia da China utiliza-se dessas prerrogativas (capacidade econômica) para desencadear uma estratégia internacional que permita ao país, nesse quadro de transição sistêmica, ampliar seu espaço de atuação internacional buscando as linhas de menor resistência.

PALAVRAS-CHAVE: China; economia continental; efeito gravitacional.

\section{INTRODUÇÃO}

O presente trabalho tem por objetivo discutir como a formação de uma economia continental na China tem se transformado em um fator de projeção desse país no sistema internacional. Não se trata de esgotar o multifacetado processo de desenvolvimento da economia chinesa ${ }^{1}$, mas de analisar como isso afeta o peso relativo do país e sua estratégia em um mundo em transformação. $\mathrm{O}$ argumento central sugerido neste artigo é que o desenvolvimento da economia continental e a ampliação da capacidade econômica tornam-se um instrumento da política externa chinesa. Em outras palavras, a China tende a criar um forte efeito gravitacional em escala global e utilizarse disso como parte de sua estratégia internacional.

\footnotetext{
${ }^{1} \mathrm{Na}$ interessante tese intitulada "Projeto nacional, desenvolvimento e socialismo de mercado na China de hoje", Elias Jabbour (2010) ocupa-se de esmiuçar diversos aspectos do desenvolvimento chinês, passando pela relação mercado-Estado, pela diversidade das estruturas produtivas do país, pelo papel do sistema financeiro, pelas mudanças no espaço agrário, pelos desafios ambientais e pela problemática questão regional.
}

O intuito é problematizar com análises recorrentes sobre o processo de desenvolvimento e de inserção internacional da China. Por um lado, aquelas que (GILPIN, 2004, p. 377) descreveram a economia chinesa como "oca", ou seja, dependente dominantemente de investimentos e empresas estrangeiras, no qual o país ocupar-se-ia apenas das etapas mais simples das cadeias produtivas. Por outro, aquelas que (MEARSHEIMER, 2006) definiram a inserção chinesa como desestabilizadora $\mathrm{e}$, por isso, propensa à guerra e avessa à cooperação internacional.

Para tanto, o trabalho foi organizado da seguinte forma: na primeira parte, discorremos sobre a evolução recente do desenvolvimento chinês, centrando foco nos desafios da formação de uma economia de dimensões continentais; na segunda, abordamos como o incremento da capacidade econômica chinesa implica um crescente efeito gravitacional do país em escala global; por fim, argumentamos que a diplomacia da China utiliza-se dessas prerrogativas (capacidade econômica) para desencadear uma estratégia internacional que permita ao país, nesse quadro de transição sistêmica, ampliar seu espaço de atuação internacional buscando as linhas de menor resistência. 


\section{DESENVOLVIMENTO CHINÊS EA FORMA- ÇÃO DAECONOMIA CONTINENTAL}

O desenvolvimento da China é parte de um complexo processo de superação dos percalços decorrentes do Século de Humilhações (1839-1949). A Revolução Chinesa de 1949 lançou as bases de uma tortuosa reconstrução nacional direcionada à reorganização política, à reconstituição da integridade territorial e à promoção do desenvolvimento e da integração da economia sob a liderança do Partido Comunista Chinês (PCCh). A superação do atraso, da vulnerabilidade internacional e da fragmentação territorial têm sido objetivos centrais das lideranças nacionais ao longo do século XX, com momentos cruciais de conflitos e de correção de rumos em 1911, com a proclamação da República, em 1949, com a Revolução, e em 1978, com as reformas.

Como afirma Jabbour, "o desenvolvimento é o ponto de fusão entre o socialismo com características chinesas e o próprio projeto nacional chinês" (JABBOUR, 2010, p. 117). Nesse sentido, não há dúvidas de que a política de Reforma e Abertura (1978) conseguiu corrigir os rumos e inaugurar o sólido processo de desenvolvimento que se estende até a atualidade ${ }^{2}$. Essa política esteve voltada à superação tanto de vulnerabilidades herdadas do Século de Humilhações quanto de concepções decorrentes da experimentação das primeiras décadas de gestão do PCCh, em especial o conturbado período da Revolução Cultural.

O governo chinês teve de apreender com as dificuldades soviéticas e com o dinamismo regional asiático (Japão e tigres asiáticos), assim como resistir às instabilidades domésticas e internacionais do final do século XX: a repressão na Praça da Paz Celestial (1989), a desintegração da União das Repúblicas Socialistas Soviéticas (URSS) (1991), o militarismo dos Estados Unidos da América (EUA) na Guerra do Golfo (1991), o veto norte-americano ao ingresso chinês na Organização Mundial do Comércio (OMC), a venda de armas a Taiwan, as provocações em relação ao Tibet, o bombardeio da Organização do Tratado do Atlântico Norte (OTAN) à embaixada chinesa em Belgrado (1999), as disputas territoriais no Mar da China, a crise financeira de 1997 etc. De todo modo, no $3^{\circ}$ Pleno do XIV

2 Para uma visão panorâmica da história recente das relações internacionais da China e da Ásia do Leste, ver Vizentini e Rodrigues (2000).
Comitê Central, em 1993, Deng conseguiu restabelecer a coesão política, consolidar a direção das reformas e enfrentar tais instabilidades.

Em razão também da conjuntura adversa, as reformas chinesas foram cautelosas, fortalecendo os instrumentos de planejamento do Estado e estabelecendo experiências próprias, com um gradualismo distinto da de outros países ${ }^{3}$ e sem a adoção de políticas liberalizantes tão em voga a partir dos anos 1980. Como destaca Medeiros (1999, p. 398-399), as reformas redefiniram a relação entre planejamento e mercado, promovendo as exportações e protegendo o mercado interno; reformando empresas e estimulando estatais; combinando preços de mercado com outros regulados etc. Ou seja, a obsessiva busca pela modernização deu-se com a ampliação das capacidades estatais e com uma integração seletiva ao sistema internacional.

O grande desafio do desenvolvimento chinês tem dependido da formação da economia continental e, por isso, de três eixos principais: a integridade territorial, a integração física do espaço nacional e a promoção do mercado interno. O primeiro eixo é o desafio do governo chinês de preservar a integridade territorial de cerca de 9,5 milhões $\mathrm{km}^{2}$, superando vulnerabilidades que remontam ao século XIX. Nesse contexto, a China esteve à beira de ser completamente fragmentada territorialmente, sob domínio estrangeiro e dos senhores de guerras (SPENCE, 1995, p. 141, 169, 235) e imerso em convulsões sociais, corrupção política e desorganização da economia nacional. Daí o objetivo da Nova China (1949) em perseguir a unidade territorial, evitando ameaças separatistas no Xinjiang e no Tibete e recuperando a ilha de Taiwan, depois da retomada de Hong Kong (1997) e Macau (1999).

O segundo eixo é a integração física do espaço nacional, essencial para superar o isolamento regional-local de uma sociedade com histórico camponês-feudal; enfrentar as desigualdades re-

3 Tanto nos países que abandonaram o socialismo real (Bloco Soviético) quanto em países em desenvolvimento (Brasil, Argentina, México etc.), a adoção dos ajustes neoliberais orientados pelo Consenso de Washington e pelos organismos multilaterais (Banco Mundial e Fundo Monetário Internacional (FMI)) tiveram efeitos trágicos como estagnação e/ou declínio da economia. Para uma crítica do neoliberalismo, sugere-se Chang (2009). Já para uma comparação entre a trajetória soviético-russa com a chinesa em relação ao ritmo e enfoque das reformas, cabe ler Medeiros (2008) 
gionais e sociais já herdadas do período anterior à revolução e aprofundadas com o início da modernização e debelar as ameaças separatistas de regiões interioranas, em especial as de minorias nãohan. Em outras palavras, o governo chinês precisa integrar territorialmente aquilo que Khanna (2008, p. 387) chama de "as quatro Chinas" nucleadas por Pequim (Nordeste), por Shanghai (Sudeste), pelo Tibete (Sudoeste) e pelo Xinjiang (Noroeste).

Com efeito, os investimentos públicos em obras de infraestrutura e as políticas para interiorizar o desenvolvimento têm sido fundamentais, apesar de eventuais resistências das elites ligadas às províncias mais desenvolvidas (litorâneas). No entanto, depois da crise financeira asiática de 1997, ficou evidente para o governo chinês a necessidade e as potencialidades do mercado doméstico face às instabilidades da economia internacional. Em razão disso, em 1999 foi criado o projeto Grande Desenvolvimento do Oeste, com vistas a reduzir as desigualdades regionais e integrar a economia nacional, sobretudo com investimentos nas províncias mais longínquas e pobres. Outro exemplo dos objetivos do governo chinês para interiorizar o desenvolvimento foi a elevação, em 1997, de Chongqing à condição de municipalidade diretamente administrada pelo governo central, com o mesmo status de Pequim, Tianjin e Shanghai. Tudo isso visando transformá-la em um centro da integração territorial do país, aproveitando-se do papel do rio Yang-Tsé como hidrovia e centro gerador de energia (Três Gargantas) que a conecta a Shanghai ${ }^{4}$. A metrópole, com quase 33 milhões de habitantes, é reflexo da prioridade dada à modernização e à integração do espaço nacional. $\mathrm{O}$ fato é que, como aponta o relatório da Organização das Nações Unidas $(\mathrm{ONU})^{5}$, os volumosos

4 Para ilustrar, seria um processo similar ao pensado para Brasília, que serviria de núcleo de conexão com as áreas interioranas, como o Centro-Oeste e o Norte do Brasil. Não difere muito também do caso de Chicago, nos EUA, que se transformou, na segunda metade do século XIX, no centro dinâmico do meio-oeste e "ponte" para unificação nacional com o Oeste norte-americano. Para informações sobre Chongqing, ver o site oficial (CHONGQUING MUNICIPAL GOVERNMENT, 2011).

5 Segundo o relatório Economia e Sociedade da Ásia e Pacífico 2008, o desenvolvimento do Oeste da China tem sido expressivo, com redução da distância do Produto Interno Bruto (PIB) per capita entre o Leste e o Oeste do país, aumento do investimento em infraestrutura e elevação do padrão de consumo. Ver China Radio Internacional (2008). investimentos públicos têm contribuído para dinamizar tais regiões ${ }^{6}$ e diminuir as disparidades sociais.

O terceiro eixo está relacionado com o desenvolvimento e o fortalecimento do mercado interno. Na China da atualidade, o desafio central é enfrentar os desníveis sociais e regionais decorrentes de uma formação complexa em que convive a economia natural de subsistência, a pequena produção mercantil, a indústria rural privada e coletiva (empresas de Cantão e Povoado), o capitalismo privado e de Estado e o socialismo (JABBOUR, 2010, p. 143-144). A transformação ocorre a partir da decomposição da economia natural (autoconsumo e/ou não monetária) por meio de dois vetores fundamentais: de um lado, a especialização da agricultura, a ampliação da produção de bens agrícolas para a cidade e o aprofundamento da integração com o mercado e, de outro, o êxodo rural e o emprego nos setores industriais e de serviços. Como conseqüência, a urbanização provoca o aumento da procura por bens agrícolas e o ganho de produtividade agrícola, uma vez que há a substituição do fator trabalho pelo fator capital, expresso, sobretudo, em novas tecnologias (RANGEL, 2005, p. 165-167 e p. 185). Cabe ilustrar que na China, nas últimas duas décadas, a melhora das condições técnicas, como a elevação no número de tratores por 100 $\mathrm{km}^{2}$ de 66 para quase 300 , gerou a ampliação de $125 \%$ na produção de alimentos mesmo com o declínio de 824 para 740 milhões de habitantes rurais (WORLD BANK, 2011).

No caso chinês, a grande abundância de mão de obra gerada pela decomposição da economia natural não tem sido impeditivo aos elevados investimento em capital fixo e tampouco ao crescente aumento de salários, em grande medida devido às ações voltadas à ampliação da demanda externa que garantem o ritmo acelerado de modernização. Na verdade, as altas taxas de crescimento, a urbanização e a elevação salarial média têm gerado o adensamento do mercado interno, produzindo a necessidade de serviços e produtos que antes não eram colocados no âmbito da economia natural. É o caso, por exemplo, de aparelhos e serviços urbanos, como abastecimento de água, transporte coletivo, iluminação pública (e

6 Recomenda-se a leitura do livro The Economy of Tibet (LI, 2008). 
privada), atendimento de saúde, redes de escolas etc., bem como de bens industriais que antes eram produtos de autoconsumo, como alimentação e produtos têxteis. Para ilustrar, entre 1990 e 2010, o consumo de energia per capita foi de 511 para mais de $2800 \mathrm{~kW} / \mathrm{h}$ e a quantidade de usuários de internet e de celular foi de zero para $30 \%$ e quase $60 \%$, respectivamente (idem).

A ampliação do mercado interno de $35 \%$ para $55 \%$ do PIB foi, inclusive, uma determinação do $12^{\circ}$ Plano Quinquenal (PQ) (2011-2015). No mesmo sentido, o $12^{\circ} \mathrm{PQ}$ prevê a estruturação de um sistema de seguridade social e um conjunto de políticas sociais para melhorar o padrão de vida, reduzindo os problemas da distribuição de renda e, por sua vez, conferindo mais estabilidade política ao país. Com efeito, os programas sociais tenderão a liberar parte da elevada poupança para o consumo o que, juntamente com a meta de implantação de um sistema de salário mínimo e de ampliação de seu poder de compra, deverão fortalecer sobremaneira a economia chinesa (CHINESE GOVERNMENT, 2011). O alargamento do mercado interno nas últimas duas décadas pode ser mensurado pela elevação do PIB per capita em poder de paridade de compra de 800 para mais de sete mil dólares e pelo crescimento da população urbana de 311 para quase 600 milhões de habitantes urbanos, sendo que saltou de $9 \%$ para quase $18 \%$ vivendo em cidades com mais de um milhão de habitantes (idem).

Enfim, as reformas colocaram em outro patamar o desenvolvimento chinês, aproximando o país do grande desafio de formar uma economia continental em sintonia com a Terceira Revolução Industrial (OLIVEIRA, 1998, p. 5)7. Mesmo com uma renda per capita baixa, a China já se converteu em uma locomotiva da economia mundial, na condição de maior exportador (2009) e segundo maior PIB (2010) do mundo ${ }^{8}$. No médio prazo,

\footnotetext{
7 Segundo Oliveira (1998), a "primeira revolução", que ocorreu com a proclamação da República (1911), esteve associada à resistência ao imperialismo japonês; a "segunda revolução", com a Revolução de 1949, coincidiu com o alinhamento com a URSS e posterior isolamento internacional (1962) e a "terceira revolução", com as Reformas (1978), articulou-se com o inicial alinhamento com os EUA e, que, obviamente, transformou-se em competição.

8 Em 2009, a China exportou mais de US\$ 1,2 trilhão de dólares, ultrapassando a Alemanha (CHINA ULTRAPASSA A ALEMANHA, 2010) enquanto o PIB
}

como o PIB chinês está artificialmente reduzido em dólares em razão da desvalorização da moeda, a tendência é que a valorização cambial amplie o PIB nominal do país (juntamente com sua capacidade financeira) sem, contudo, comprometer o desempenho do comércio exterior chinês (já que se dará em compasso com a evolução da competitividade). Conseqüentemente, a consolidação de uma economia continental na China fortalece o mercado interno e amplia o peso da economia ${ }^{9}$ sobre a região e o mundo. A elevação dos preços das commodities é apenas a "ponta do iceberg" de um mercado de potencial surpreendente.

\section{CAPACIDADE ECONÔMICA E EFEITO GRAVITACIONAL}

O desenvolvimento da economia continental na China e o fortalecimento de sua projeção internacional têm se dado de maneira articulada. Na verdade, a capacidade econômica tem sido um instrumento fundamental à universalização da política externa chinesa (PAUTASSO, 2009). Da mesma forma, "é esse grande mercado interno o centro de gravidade da dinâmica econômica asiática" (MEDEIROS, 2006, p. 77). Portanto, é possível sugerir que a capacidade econômica da China cria uma espécie de efeito gravitacional que, por sua vez, permite à diplomacia chinesa explorar essas vantagens sem ter de confrontar a ordem mundial.

De qualquer forma, o fortalecimento da posição internacional do país oriental tem dependido do seu planejamento das relações econômicas internacionais. Primeiro, o controle do câmbio em patamares competitivos explicam parte do desempenho exportador do país. Mais do que a oferta de mão de obra a baixo custo, as condições macroeconômicas como moeda desvalorizada, crédito estatal abundante e taxas de juros baixas são, combinadas a um conjunto de políticas industriais, comerciais e tecnológicas, estímulos governamentais à conquista de mercados externos. Some-se a isso a opção comercial agressiva voltada para transformar nichos em mercados de massa, obtendo ganhos de escala com margens de lucro menores.

alcançou US\$ 5,878 trilhões, superando o do Japão, com US\$ 5,474 trilhões (CHINA SUPERA JAPÃO, 2011).

9 Segundo China Radio Internacional (2010), no ano da crise, 2009, a China representou $50 \%$ do crescimento mundial. E a perspectiva para os próximos anos é que possa contribuir com um terço do crescimento mundial. 
Segundo, a adoção de uma política de atração de investimentos externos diretos (IEDs) por meio de uma eficaz regulação estatal. A criação das Zonas Econômicas Especiais (ZEEs) talvez elucide de modo mais claro a concepção das reformas e o papel do planejamento. De quatro ZEEs iniciais (Shenzhen, Zhuhai, Shantou e Xiamen) criadas na primeira metade da década de 1980 , as áreas especiais foram diversificando-se em formato institucional e econômico ${ }^{10} \mathrm{e}$ distribuindo-se pelo território como polos irradiadores da modernização. No caso dos investimentos externos diretos, também houve experimentação e regulação ${ }^{11}$, criando restrições aos investimentos exclusivamente estrangeiros e estímulos aos investimentos com gestão conjunta (joint ventures). Ao fomentar joint ventures com capitais chineses ${ }^{12}$, o governo estimulava as transferências tecnológicas e de técnicas de gestão, ao mesmo tempo em que condicionava a geração de saldos comerciais e preservava a capacidade decisória em território nacional.
Isso significou que o Estado chinês preservou a prerrogativa política sobre o planejamento econômico e pôde criar mecanismos de internalização e difusão do desenvolvimento, reduzindo as vulnerabilidades e criando uma estratégia de integração do país à economia mundial. Diferente da visão de que a China desenvolvia-se como economia de enclave, baseada na exportação de bens a partir da absorção de investimentos estrangeiros (GILPIN, 2000, p. 378), a dinâmica do país oriental permaneceu fortemente assentada no investimento público, na exportação de empresas estatais e na expansão doméstica do consumo (MEDEIROS, 2006, p. 75). Os dados posteriores às reformas de 1978 são ilustrativos (Gráfico 1). Em outras palavras, o governo chinês tem sabido explorar os investimentos estrangeiros e o mercado mundial para dotar suas empresas de capacidade de competição global; isso explica como a China está a ampliar o grau de agregação de valor das exportações, a presença internacional de suas empresas estatais e o volume de investimentos no exterior ${ }^{13}$.

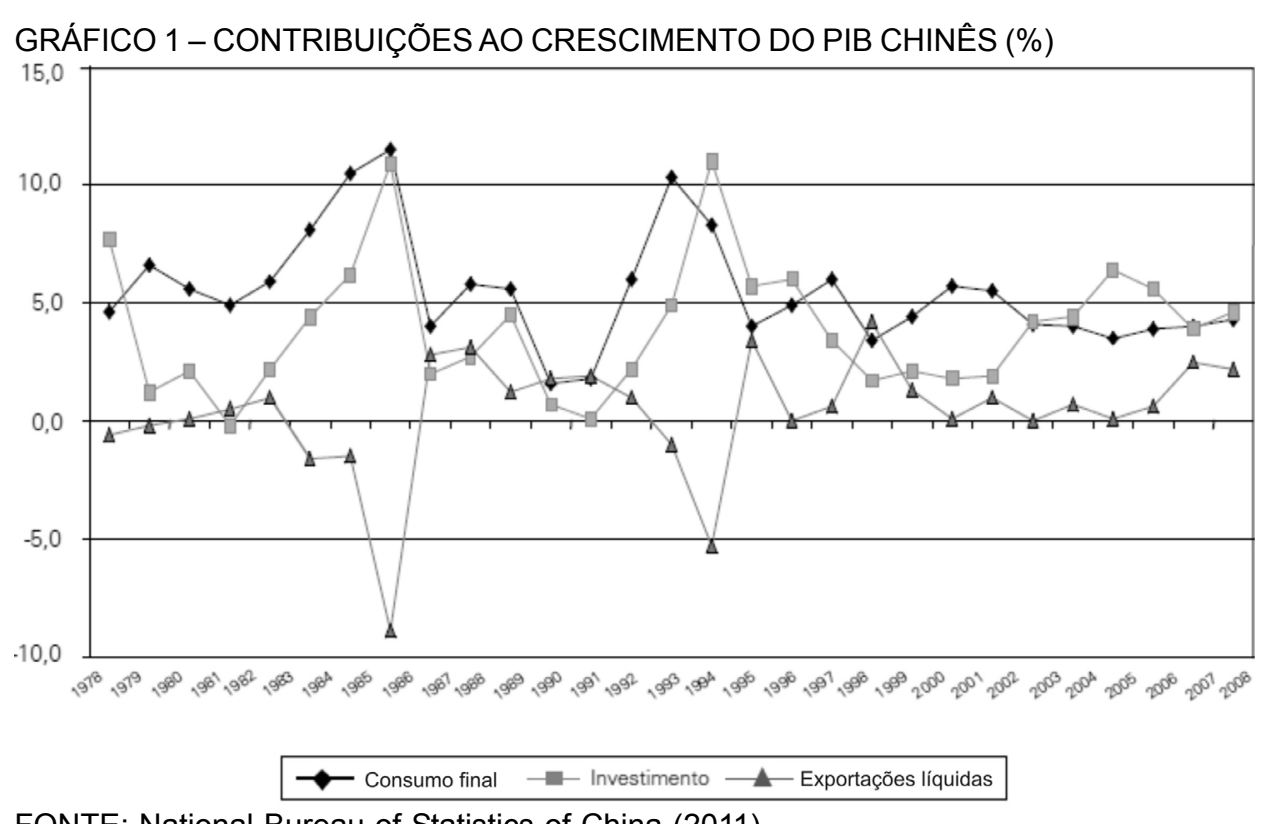

FONTE: National Bureau of Statistics of China (2011).

10 Foram criadas as Zonas de Desenvolvimento Econômico e Tecnológico; as Zonas Francas; as Zonas de Desenvolvimento de Indústrias de Alta e Nova Tecnologia; as Zonas Fronteiriças de Cooperação Econômica e Zonas de Processamento de Exportação (KE \& JUN, 2004, p. 230-240).

11 Os documentos "Regulamento de Orientação do Investimento Estrangeiro na China" e "Catálogo Guia de Investimento Estrangeiro em Setores Econômicos" definiam setores a serem estimulados, admitidos, restringidos e proi- bidos. Da mesma forma, criavam regras para transferência de tecnologia, fluxos de capitais, entre outros mecanismos (idem, p. 240-248)

12 Cabe salientar que a participação de empresas estrangeiras nas exportações chinesas aparece inflacionada nas estatísticas, pois grande parte destas tem sociedade com capitais nacionais.

13 Recomenda-s a leitura do Comunicado n. 84 do IPEA, "Internacionalização das empresas chinesas: as prioridades do investimento direto chinês no mundo" (IPEA, 2011). 
Em terceiro lugar, o fortalecimento das reservas internacionais do país como forma de proteção diante de instabilidades financeira internacionais. No âmbito doméstico, a capacidade econômica (financeira), formada pelos saldos comerciais, pelas reservas internacionais e pela poupança, cria as condições para uma política de crédito expansiva (investimento e consumo) produzindo taxas altas de formação de capital ( $47 \%$ do PIB) e um mercado interno dinâmico. No âmbito internacional, a capacidade econômica chinesa permitiu ao país tornarse uma alternativa de comércio, investimento e crédito para os países periféricos. Mesmo que a economia norte-americana preserve a primazia, incluindo a condição do dólar de reserva e ativo internacionais, os países emergentes romperam com o exclusivismo do Ocidente e de seu sistema de Bretton Woods (FMI e Banco Mundial). Basta olhar a distribuição das reservas internacionais e os credores dos títulos do Tesouro dos EUA.

Assim, a relação entre a formação da economia continental, o incremento da capacidade econômica e o efeito gravitacional chinês têm se feito sentir de maneira mais evidente na esfera regional, por meio do que denominamos de (re)constituição do sistema sinocêntrico (PAUTASSO, 2011a). É na estruturação de um sistema regional sinocêntrico que se percebe como tal relação explica a estratégia de ascensão da China, a dinâmica de integração asiática e seus desdobramentos sobre a transição sistêmica.
O protagonismo da China tem sido percebido em todas as esferas da dinâmica regional. Na esfera institucional, a diplomacia chinesa passou a ingressar em mecanismos de integração regionais, como Asian-Pacific Economic Cooperation (APEC), Asean+3, Asia-Europe Meeting (ASEM), Fórum de Cooperação América Latina-Ásia do Leste (Focalal), e mesmo a liderar outros processos, como a Organização de Cooperação de Shanghai (OCS). Na esfera geográfica, a integração da economia chinesa tem impulsionado a conexão entre a Bacia do Pacífico e a Eurásia por meio da Ásia Central, com obras de infraestrutura energética e de transportes e ampliação do comércio, dando uma feição moderna à antiga interligação da Rota da Seda. Na esfera comercial, a economia chinesa tornou-se o maior parceiro comercial da maioria dos países da região, sendo que mais da metade do comércio chinês está voltado à Ásia-Pacífico (Gráfico 1). Na esfera política, além de ser membro permanente do Conselho de Segurança da ONU, a China goza de uma autonomia decisória que outros países da região não possuem, o que explica a liderança em contenciosos como na península coreana (Grupo dos Seis). Na esfera populacional-cultural, é preciso sublinhar que há uma histórica presença de populações chinesas na Ásia que representam, não obstante eventuais tensões, uma rede de negócios e uma influência cultural decisiva, pois estes conhecem os sistemas legais, os referenciais de valores e o ambiente de negócios ${ }^{14}$.
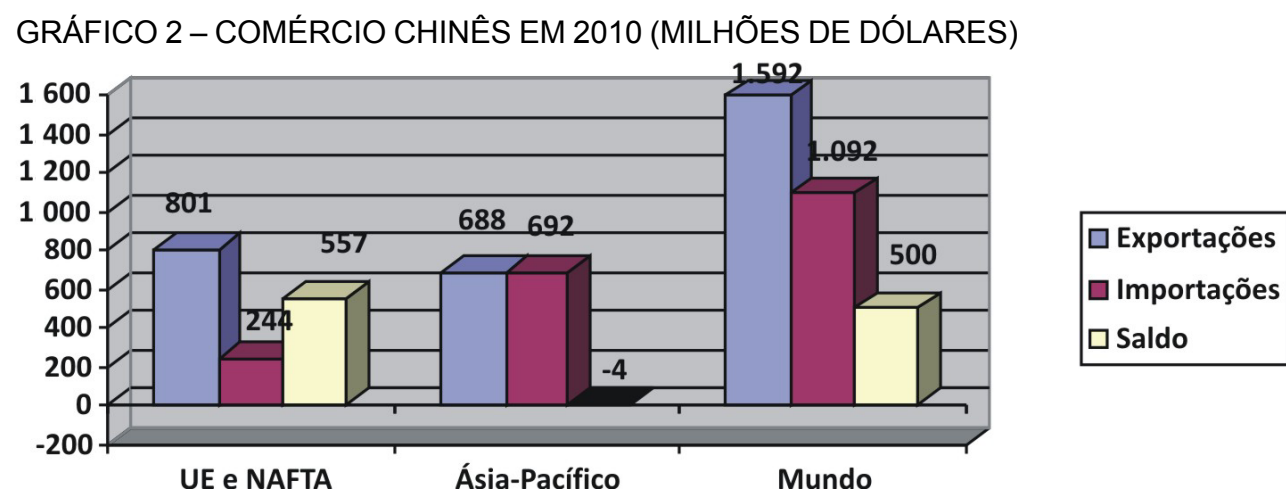

FONTE: Euromonitor International (2011).

Cabe tentar compreender como a reconstituição do sistema sinocêntrico está a sintetizar elementos novos e velhos da região. De um lado, a longa tradição do sistema regional asiático baseou-se na baixa freqüência de guerras entre os estados, nas
14 São cerca de 55 milhões de chineses no Sudeste Asiático com recursos financeiros desproporcionais ao seu contingente populacional na Malásia, na Tailândia, na Indonésia e nas Filipinas, além dos três quartos de população chinesa em Cingapura (ver PINTO, 2000, p. 44). 
raras redefinições territoriais ${ }^{15}$, na ausência de competição entre si para construir impérios ultramarinos e no reduzido ímpeto de envolverem-se em corridas armamentistas em comparação com o sistema europeu, em que a combinação peculiar entre capitalismo, militarismo e territorialismo criou as condições competitivas para a dominação em escala global (ARRIGHI, 1998, p. 324, 328; FIORI, 2009). Isso explica a razão pela qual o desenvolvimento chinês não revela nem comportamento revisionista nem mentalidade expansionista, de modo que a prioridade é a integridade territorial em vez da reprodução do militarismo japonês-alemão (GOLDSTEIN, 2003, p. 86) ${ }^{16}$.

Na atualidade, a integração asiática está baseada em um sistema hierárquico cujas características diferem substancialmente do sistema westphaliano: os estados mais fracos buscam benefícios em vez do balanceamento frente ao mais forte; o Estado central busca minimizar os conflitos com os países mais fracos, provendo meios para ajustar-se a circunstâncias imprevistas; a hierarquia é sustentada não somente pelo poder material, mas por normas culturais compartilhadas que servem para mitigar o dilema de segurança e aumentar o nível de comunicação e confiança entre os estados do sistema; por fim, o Estado central tem baixo nível de interferência nos assuntos dos países mais fracos, respeitando a autonomia na organização doméstica e nas relações exteriores. Portanto, enquanto o sistema regional asiático considera que há uma hierarquia formal e uma igualdade informal; no sistema europeu reconhece-se uma igualdade formal entre os países e uma hierarquia informal que expõe na prática poderes desproporcionais (KANG, 2003, p. 167-168) ${ }^{17}$.

15 Conforme Kang (2003, p. 170), em 1500 a Europa possuía cerca de 500 unidades territoriais, já em 1900, cerca de 20. O mapa europeu mudou sensivelmente nos períodos do Entre Guerras, da Guerra Fria e depois dela, com o surgimento e o desaparecimento de países e impérios. No caso da Ásia, os ciclos de violência explicam-se, em parte, em razão da diluição do sistema hierárquico e na conversão "realista" de países como o Japão.

16 Conforme Goldsten (2003, p. 86), a China tem adotado uma estratégia neobismarckiana voltada à realização de seus interesses e com baixo grau de tensionamento; o que não sugere a inexistência de riscos internacionais, sobretudo.

17 O sistema hierárquico da região elucida, por exemplo, as razões pelas quais $(i)$ os países asiáticos reagem de maneira diferente à dos EUA na questão de Taiwan (inclusive
Enfim, analisando em perspectiva história, é possível elucidar as mudanças na geografia do poder na região e a estratégia de inserção internacional chinesa. A saída dos EUA do Vietnã permitiu à China sua reinserção no mundo e a ampliação de sua presença na Ásia. Com o Acordo Plaza, em 1985, a China começou a beneficiar-se do impulso desenvolvimentista na região, gerado pelo sistema de subcontratação e transplante da ponta de menor valor agregado do sistema produtivo japonês (ARRIGHI, 1998, p. 110-114). Isso ocorreu porque, mesmo deslocando outros países produtores de bens de consumo de terceiros mercados, a China ampliou muito a sua demanda e, conseqüentemente, as exportações asiáticas, provocando um efeito gravitacional ainda mais notável (MEDEIROS, 2006, p. 81). A crise do milagre japonês a partir dos anos 1980 e o fim da URSS, em 1991 deslocaram, progressivamente, o epicentro para a China devido ao dinamismo econômico-comercial e ao fim das fraturas ideológicas oriundas da bipolaridade e da ruptura sinosoviética.

\section{A ESTRATÉGIA INTERNACIONAL CHINE- SAE A TRANSIÇÃO SISTÊMICA}

Da mesma forma que o desenvolvimento da economia continental norte-americana moldou a história do século XX, consagrando instituições internacionais a ela associadas, o mesmo processo na China também produzirá impacto notável na ordem mundial em meados do século XXI (JABBOUR, 2010, p. 214). Se a transição sistêmica em curso e a ascensão chinesa são irrefreáveis, resta, isso sim, acompanhar e compreender como a ordem mundial vai adaptar-se à China e esta irá moldá-la ao fornecer novas soluções sistêmicas (ARRIGHI \& SILVER, 2001, p. 296).

Os contextos de transição sistêmica são caracterizados pelo rearranjo de forças no sistema internacional, o que se desdobra na abertura de espaços para os países emergentes. Ironicamente, desde a década de 1970, em especial após a Guerra Fria, a máxima expansão sistêmica dos EUA coincidiu com a intensificação da competição entre suas unidades, reflexo da multiplicação de estados soberanos, posterior à descolonização afro-asiática, e da ascensão de novos polos de

o Japão) e (ii) países como Vietnã e Coréia do Norte aceitam a posição central da China na região (ver KANG, 2003). 
poder, com destaque para a Ásia e a China (FIORI, MEDEIROS \& SERRANO, 2008, p. 24, 66). A crescente competição interempresarial e interestatal é parte da transição sistêmica, evidente na readequação das bases territoriais de acumulação do capital, na formação de novos arranjos político-diplomáticos entre os espaços global e nacional e nas transformações sociais decorrentes de uma ampla reestruturação do capitalismo (ARRIGHI \& SILVER, 2001, p. 39).

Nesse quadro de reorganização de forças, a China tem sido mais do que um simples país em desenvolvimento, mas um típico país emergente, já que está experimentando a ampliação dos recursos de poder e da capacidade de contribuir para a gestão do sistema internacional, ao passo que se torna mais legítimo para desempenhar um papel relevante na arena internacional (HURRELL, 2009, p. 22). Quer dizer, além da ampliação de suas capacidades materiais, a China tem tido uma inserção internacional em escalas regional e global, ao mesmo tempo em que se integra plenamente à economia mundial e aos organismos multilaterais. Esse maior envolvimento na política e nos negócios internacionais vem acompanhado de uma maior autonomia na capacidade de formulação de sua estratégia internacional.

Como mais evidente potência emergente, a China combina ações diplomáticas voltadas à preservação da estabilidade e à reforma do sistema internacional. Isto é, a defesa do status quo permite ao país acumular forças e garantir certa segurança (hedging) ao passo que busca uma acomodação à nova realidade internacional (FOOT, 2009, p. 125-152). Nesse sentido, a diplomacia chinesa tem estabelecido uma estratégia que combina (i) a integração ao sistema internacional, (ii) o envolvimento cada vez mais expressivo com os países do Sul por reformas do sistema e (iii) a condição de líder do espaço regional.

A integração chinesa ao sistema internacional tem se dado de modo gradual desde a liderança de Deng Xiaoping e, especialmente, após a Guerra Fria. Por isso, a China aderiu aos regimes de controle de armamentos (Tratado de Não-Proliferação Nuclear; à Convenção de Armamentos Químicos; à Convenção de Armamentos Biológicos e ao Tratado para a Proibição Completa de Testes Nucleares); passou a envolver-se em operações de paz coordenadas pela ONU; apoiou $84 \%$ das resoluções do Conselho de Segurança da ONU, abstendo-se das demais; realizou concessões substantivas a fim de ingressar na OMC; integrou o Banco Mundial e virou o maior tomador de créditos; assinou pactos voltados à defesa das instituições e direitos civis (Pacto Internacional dos Direitos Econômicos, Culturais e Sociais, Pacto Internacional de Direitos Civis e Políticos), entre outras ações (idem, p. 24-28).

Isso também revela que a política externa chinesa tornou-se crescentemente assertiva e passou a fortalecer sua atuação multilateral desde meados dos anos 1990. Até então, o ceticismo chinês com relação à atuação multilateral devia-se à percepção de que o país sofria nesses fóruns as pressões e as manipulações dos EUA e do Japão. Tal mudança de comportamento representa o objetivo de reduzir as percepções de ameaça e os riscos do isolamento, de diversificar e ampliar a interdependência com várias regiões do globo e de fortalecer suas forças armadas para desenvolver capacidade dissuasória (GOLDSTEIN, 2003, p. 61-85). Apesar da assimetria de poder, as organizações internacionais também poderiam restringir a atuação do Ocidente e dos EUA e equilibrar a ordem mundial por meio da aproximação com outros países do Sul.

A mudança de uma atuação internacional defensiva e voltada às relações bilaterais para um maior ativismo diplomático no âmbito multilateral revela também outro nível de engajamento da diplomacia chinesa. Cabe destacar a participação em organismos internacionais (FMI, Banco Mundial e OMC), o envolvimento em mecanismos de integração regionais voltados à segurança (OCS) e as ações direcionadas ao combate de ameaças não tradicionais $\left(\mathrm{SARS}^{18}\right.$, terrorismo e tráfico de drogas) à estabilidade do desenvolvimento chinês (WANG, 2005, p. 159-165).

Paralelamente, o governo chinês atua para liderar os países do Sul, visando a mudanças e/ou resistência frente assimetrias da ordem mundial. Por isso, a diplomacia da China tem enfatizado tanto a defesa da soberania quanto sua identidade de semicolônia e país subdesenvolvido - embora seja membro do Conselho de Segurança da ONU, tenha armas nucleares e tenha poder econômico crescente, incluindo a condição de segundo mai-

18 Severe Acute Respiratory Syndrome (Síndrome Respiratória Aguda Severa). 
or PIB mundial (FOOT, 2010, p. 31). O fato é que a China tem buscado um espaço próprio, reafirmando-se como alternativa ao Ocidente para os países periféricos, na medida em que defende um modelo de interação internacional baseado nos ganhos mútuos, como são os casos das teses oficiais do "mundo harmonioso" e/ou do Consenso de Pequim. Contudo, o desafio dos EUA é que a China está beneficiando-se tanto da aceitação das próprias regras formuladas pelo Ocidente (BRESLIN, 2010, p. 55), quanto dos modelos alternativos que o país oriental tem proposto.

A política externa chinesa parece ter percebido que a cooperação Sul-Sul é cada vez mais uma realidade da diversificação do cenário internacional e uma estratégia para tal. O caso das relações sino-africanas é ilustrativo do fortalecimento do eixo Sul-Sul, seja pela evolução da interação econômica (comércio e investimentos), seja pelo incremento do diálogo diplomático, como atesta o Fórum de Cooperação China-África (PAUTASSO, 2010a; 2010b). Enquanto a Europa perdia ímpeto e os EUA priorizavam outras regiões, os países emergentes (China, Índia e Brasil) aproveitam as oportunidades que se abriam no continente africano com a virada do século.

Em razão da capacidade limitada de atuar na arena internacional, o espaço regional também representam oportunidade para os países emergentes assumirem iniciativas mais ousadas. No caso chinês, a região, que até o fim da Guerra Fria era percebida com desconfiança, passou a representar o foco central do engajamento e da cooperação para dirimir ameaças à segurança (isolamento, separatismos e epidemias) e impulsionar a integração econômica regional (BRESLIN, 2010, p. 33-38). A reconstituição de um sistema sinocêntrico revela a reorganização das forças e o maior engajamento chinês na região.

Essas características da integração da China ao sistema internacional indicam também que a transição em curso tem particularidades em relação às demais. A ordem mundial constituída após a II Guerra Mundial, sob liderança dos EUA, possui um sistema de regras e instituições bastante denso, abrangente e legítimo e, ao mesmo tempo, uma estrutura hierárquica de poder (inclusive nuclear) muito expressivo. Isso favorece tanto a acomodação quanto limita a subversão da ordem existente. Com efeito, os EUA não podem impedir a ascensão da China, mas podem contribuir para acomodá-la à nova ordem (IKENBERRY, 2010, p. 71-72, 80). Não interessa, portanto, à China subverter a ordem mundial justamente porque tem sido a grande beneficiada do status quo; interessa ao país oriental, isso sim, deslocá-la para ocupar uma posição que confira, a um só tempo, segurança e protagonismo. Fica evidente o desejo chinês de apresentar-se como uma potência cooperativa, evitando as teses de "ameaça chinesa" e o isolamento proposto pelo Ocidente (sobretudo depois de 1989), ao mesmo tempo em que explora as vantagens que a arena internacional tem propiciado.

O desafio chinês é lidar com as incertezas e rearranjos de poder que se intensificaram com o fim da Guerra Fria, bem como com uma superpotência (EUA) que tem buscado reafirmar-se como único poder, expandindo seus domínios internacionais. No campo militar, o expansionismo dos EUA deu-se sobre os antigos espaços soviéticos ao entorno da nova Rússia, incluindo a expansão da OTAN, a intervenção militar nos Balcãs, as ingerências em países como Ucrânia e Geórgia e a presença na Ásia Central, Paquistão e Afeganistão; a projeção de força sobre o Oriente Médio, com intervenções no Iraque duas vezes e a recente intervenção na Líbia e a ampliação da infraestrutura militar pelo mundo. No campo econômico, a imposição, via organismos multilaterais, de seus interesses por meio de agendas econômicas e institucionais de tipo neoliberal fortaleceu os movimentos sociais de resistência às reformas impopulares, bem como regimes de centro-esquerda. No campo diplomático, o uso de instrumentos ideológicos como "intervenção humanitária", "ataque preventivo" e "direito de proteger" recrudesceu a arbitrariedade do poder e forçou a criação de articulações de resistência, ao passo que fragilizava as instituições mundiais.

Contudo, as duas últimas décadas não foram apenas de ofensiva diplomático-militar dos EUA, foram também de reestrutura da economia mundial, de emergência de novos polos de poder e, por sua vez, formação de novas coalizões e alinhamentos internacionais. De um lado, a dificuldade dos EUA não está somente na China, mas na capacidade da diplomacia norte-americana em renovar a liderança sob instituições multilaterais que eles próprios fragilizaram a legitimidade, como OMC, Conselho de Segurança da ONU, Tribunal Penal Internacional, Tratado de Não-Proliferação Nuclear, Protocolo de Quioto etc. De outro, a China 
explora essas contradições buscando as linhas de menor resistência para ampliar seu espaço internacional - inclusive por saber que o declínio relativo dos EUA difere de um colapso, uma vez que o país preserva instrumentos de poder cruciais, como primazia militar e financeira ${ }^{19}$. Em suma, a China tem se engajado nos organismos multilaterais e, paralelamente, rejeitado, de maneira enfática, as tentativas de normatizar o desenvolvimento (câmbio, instituições etc.) e/ou ameaçar a segurança (Tibete, Taiwan etc.).

\section{CONCLUSÕES}

A inserção chinesa é resultado de uma mudança que o país oriental teve de operar na sua estratégia internacional para poder viabilizar a correção de rumos no modelo de desenvolvimento nacional. Não foi apenas mudança de discurso; o governo chinês, a partir dos anos 1970, modificou sua diplomacia de maneira substantiva, mesmo que sem sobresssaltos, para superar o isolamento internacional e os percalços internos. Isto é, a China explorou novas coalizões e estratégias para adequar os desígnios de modernização às alterações de dinâmica do cenário mundial. A aproximação com os EUA nos anos 1970-1980 e o fim da bipolaridade nos anos 1990 exigiu da política externa chinesa capacidade de reagir a mudanças drásticas de alianças e de correlação de forças, assim como de disputas internas e de reações internacionais.

19 Os EUA ainda possuem ascendência sobre as estruturas hegemônicas de poder nos campos financeiro (FMI, Banco Mundial e dólar), militar (OTAN, Anzus (Australia, New Zealand and United States Treaty) e Seato (Southeast Asia Treaty Organization)), político (ONU), comercial (OMC) etc.
A diplomacia chinesa tem, portanto, optado pelo fortalecimento do multilateralismo, por meio do envolvimento tanto em organismos consagrados pela ascendência ocidental quanto em novos mecanismos multilaterais com a região e/ou no âmbito Sul-Sul. A diversificação das alianças e das coalizões amplia a atuação chinesa no cenário internacional, obtendo instrumentos para promover o desenvolvimento nacional e evitando eventuais tentativas de isolá-la. A estratégia da China combina um esforço de desenvolvimento das capacidades nacionais e de promoção de novas parcerias internacionais com um nível de compromisso econômico e diplomático internacional voltado a maximizar os benefícios de interdependência.

Trata-se de um contexto internacional de expansão competitiva entre os estados, sem, contudo, formar um único poder global, tampouco eliminar a importância e o poder das economias nacionais. E o histórico processo de oligopolização do poder e da riqueza em escala global (FIORI, 2009, p. 173) fortalece as estruturas de poder em disputa. Isso explica por que se transitou de potências no século XIX (Grã-Bretanha e França), para superpotências no século XX (EUA e URSS), e atualmente assistimos a projeção de grandes economias nacionais capazes de liderar processos de integração regionais (União das Nações SulAmericanas (Unasul), OCS, União Européia, Tratado Norte-Americano de Livre-Comércio (Nafta), Southern African Development Community (SADC), South Asian Association for Regional Cooperation (Saarc)). Embora não seja tarefa fácil, é imprescindível decifrar o nexo entre o desenvolvimento nacional e a estratégia internacional da China e seu impacto em um mundo em transformação.

Diego Pautasso (dpautasso@espm.br) é Doutor em Ciência Política pela Universidade Federal do Rio Grande do Sul (Ufrgs) e Professor de Relações Internacionais na Escola Superior de Propaganda e Marketing (ESPM).

\section{REFERÊNCIAS BIBLIOGRÁFICAS}

ARRIGHI, G. 1998. A ilusão do desenvolvimento. Petrópolis: Vozes.

ARRIGHI, G. \& SILVER, B. 2001. Caos e governabilidade no moderno sistema mundial. Rio de Janeiro: Contraponto.
BRESLIN, S. 2010. Entendendo a ascensão regional chinesa. In: SPEKTOR, M. \& NEDAL, D. (orgs.). O que a China quer? Rio de Janeiro: Fundação Getúlio Vargas.

CHANG, H. 2009. Maus samaritanos: o mito do livre-comércio e a história secreta do capitalismo. Rio de Janeiro: Elsevier. 
FIORI, J. L. 2009. O poder global e a nova geopolítica das nações. Crítica y Emacipación, Buenos Aires, Ano 1, n. 2, p. 157-183, primer semestre. Disponível em: http:// bibliotecavirtual.clacso. org.ar/ar/libros/secret/ CyE/CyE2/06opo.pdf. Acesso em: 25.set.2011.

FIORI, J. L.; MEDEIROS, C. \& SERRANO, F. 2008. O sistema inter-estatal capitalista no início do Século XXI. In: FIORI, J. L.; MEDEIROS, C. \& SERRANO, F. (orgs.). $O$ mito do colapso do poder americano. Rio de Janeiro: Record.

FOOT, R. 2009. Estratégias chinesas em uma ordem mundial global hegemônica: acomodação e hedging. In: HURRELL, A.; NARLIKAR, A.; SOARES DE LIMA, M. R.; SPEKTOR, M.; HIRST, M.; MACFARLANE, N. \& FOOT, R. Os BRICs e a ordem global. Rio de Janeiro: Fundação Getúlio Vargas.

2010. O poder chinês e a idéia de um poder responsável. In: SPEKTOR, M. \& NEDAL, D. (orgs.). O que a China quer? Rio de Janeiro: Fundação Getúlio Vargas.

GILPIN, R. 2004. O desafio do capitalismo global. Rio de Janeiro: Record.

GOLDSTEIN, A. 2003. An Emerging China's Emerging Grand Strategy: a Neo-Bismarckian Turn? In: IKENBERRY, J. \& MASTANDUNO, M. (eds.). International Relations Theory and the Asia-Pacific. New York: Columbia University.

HURRELL, A. 2009. Hegemonia, liberalismo e ordem global: qual é o espaço para potências emergentes? In: HURRELL, A.; NARLIKAR, A.; SOARES DE LIMA, M. R.; SPEKTOR, M.; HIRST, M.; MACFARLANE, N. \& FOOT, R. Os BRICs e a ordem global. Rio de Janeiro: Fundação Getúlio Vargas.

KANG, D. 2003. Hierarchy and Stability in Asian International Relations. In: IKENBERRY, J. \& MASTANDUNO, M. (eds.). International Relations Theory and the Asia-Pacific. New York: Columbia University.

KHANNA, P. 2008. The Second World: Empires and Influence in the New Global Order. New York: Random.

IKENBERRY, G. J. 2010. A ascensão da China e o futuro do Ocidente: o sistema liberal sobre- viverá? In: SPEKTOR, M. \& NEDAL, D. (orgs.). O que a China quer? Rio de Janeiro: Fundação Getúlio Vargas.

JABBOUR, E. 2010. Projeto nacional, desenvolvimento e socialismo de mercado na China de hoje. São Paulo. Tese (Doutorado em Geografia Humana). Universidade de São Paulo. Disponível em: http://www.teses.usp.br/teses/ disponiveis/8/8136/tde-18012011-103155/publico/2010_EliasMarcoKhalilJabbour.pdf. Acesso em: 25.set.2011.

KE, M. \& JUN, L. 2004. El comercio em China. Beijing: China Internacional.

LI, L. 2008. The Economy of Tibet. Beijing: Foreign Languages.

MEARSHEIMER, J. 2006. China's Unpeaceful Rise. Current History, Philadelphia, v. 105, n. 690, p. 160-162, Apr. Disponível em: http:// mearsheimer.uchicago.edu/pdfs/A0051.pdf. Acesso em. 25.set.2011.

MEDEIROS, C. 1999. China: entre os séculos XX e XXI. In: FIORI, J. L. Estado e moedas no desenvolvimento das nações. Rio de Janeiro: Vozes.

2006. Deslocamento e complementaridade: a estratégia de desenvolvimento chinesa e a economia regional asiática. Trabalho apresentado na "Conferência Nacional de Política Externa e Política Nacional: O Brasil no mundo que vem aí”. Brasília: Fundação Alexandre de Gusmão.

2008. Desenvolvimento econômico e ascensão nacional: rupturas e transições na Rússia e na China. In: FIORI, J. L.; MEDEIROS, C. \& SERRANO, F. (orgs.). O mito do colapso do poder americano. Rio de Janeiro: Record.

OLIVEIRA, P. C. 1998. Revolução e contrarevolução. São Paulo: Artpress. Disponível em: http://www.pliniocorreadeoliveira.info/ RCR.pdf. Acesso em: 25.set.2011.

PAUTASSO, D. 2009. O comércio exterior na universalização da política externa chinesa no século XXI. Meridiano 47, Brasília, v. 113, p. 14-16. Disponível em: http://www.red.unb.br/ index.php/MED/article/view/494/311. Acesso em: 25.set.2011.

2010a. A África no comércio internacional do Grupo BRIC. Meridiano 47, Brasília, v. 120 , p. 54-59. Disponível em: http:// 
www.red.unb.br/index.php/MED/article/view/ 661/757. Acesso em: 25.set.2011.

2010b. A Economia Política Internacional da China para Angola e os caminhos da transição sistêmica. Século XXI, Porto Alegre, v. 1, n. 1, p. 107-126, jan.-dez. Disponível em: http:/ /sumario-periodicos.espm.br/index.php/ seculo21/article/viewFile/1708/33. Acesso em: 25.set.2011.

2011. China, Rússia e a integração asiática: o sistema sinocêntrico como parte da transição sistêmica. Conjuntura Austral, Porto Alegre, v. 1, p. 1-16. Disponível em: http:// seer.ufrgs.br/ConjunturaAustral/article/view/ 18688/11653. Acesso em: 25.set.2011.

2011b. China e Rússia no pós-Guerra Fria. Curitiba: Juruá. 2011c. O fortalecimento das relações SulSul: estratégia e realidade para os países emergentes. Conjuntura Austral, Porto Alegre, v. 2, n. 8, p. 48-62, out.-nov.

PINTO, P. 2000. A China e o Sudeste Asiático. Porto Alegre: UFRGS.

RANGEL, I. 2005. Obras reunidas. V. 1. Rio de Janeiro: Contraponto.

SPENCE, J. 1995. Em busca da China moderna. São Paulo: Companhia das Letras.

VIZENTINI, P. \& RODRIGUES, G. 2000. $O$ dragão chinês e os tigres asiáticos. Porto Alegre: Novo Século.

WANG, F. 2005. China's Multilateral Diplomacy in the New Millennium. In: DENG, Y, \& WANG, F.-L. (eds.). China Rising. Lanham: Rowman \& Littlefield.

\section{OUTRAS FONTES}

CHINA RADIO INTERNACIONAL. 2008. Instituição da ONU confirma estratégia chinesa de Grande Desenvolvimento do Oeste, 27.mar. Disponível em: http://portuguese.cri.cn/101/ 2008/03/27/1@86014.htm. Acesso em: 25.set.2011.

2010. China lidera o crescimento econômico mundial, 15.out. Disponível em: http:// portuguese.cri.cn/561/2010/10/15/ 1s127696.htm. Acesso em: 25.set.2011.

CHINESE GOVERNMENT. 2011. Key Targets of China's 12th Five-Year Plan. Disponível em: http://www.gov.cn/english/2011-03/05/ content 1816822.htm. Acesso em: 25.set.2011.

China ultrapassa a Alemanha e se torna o maior exportador do mundo. 2010. O Globo, Rio de Janeiro, 10.jan. Disponível em: http:// oglobo.globo.com/economia/mat/2010/01/10/ china-ultrapassa-alemanha-se-torna-maior-exportador-do-mundo-915500444.asp. Acesso em: 25.set.2011.

China supera Japão como segunda potência econômica mundial. 2011. Correio do Povo, Por- to Alegre 14.fev. Disponível em: http:// www.correiodopovo.com.br/Noticias/?Noti$\mathrm{cia}=257542$. Acesso em: 25.set.2011.

\section{CHONGQUINGMUNICIPALGOVERNMENT.}

2011. Sítio de internet. Disponível em: http:// english.cq.gov.cn/. Acesso em: 25.set.2011.

EUROMONITOR INTERNATIONAL. 2011. China Country Factfile. Disponível em: http:/ /www.euromonitor.com/china/countryfactfile. Acesso em: 25.set.2011.

IPEA. 2011. Internacionalização das empresas chinesas: as prioridades do investimento direto chinês no mundo. Comunicados do IPEA, Brasília, n. 84, 6.abr. Disponível em: http:// 189.21.130.9/portal/images/stories/PDFs/comunicado/110405_comunicadoipea84.pdf. Acesso em: 25.set.2011.

NATIONAL BUREAU OF STATISTICS OF CHINA. 2011. Statistical Data. Disponível em: http://www.stats.gov.cn/english/ statisticaldata/. Acesso em: 25.set.2011.

WORLD BANK. 2011. Data. Disponível em: http://data.worldbank.org/?display=graph. Acesso em: 25.set.2011. 
THE CHINESE CONTINENTAL ECONOMY AND ITS GRAVITATING EFFECT

\section{Diego Pautasso}

The present article looks at national development and China's international positioning. Our goal is to discuss how the formation of a continental economy in China has become a factor of that country's projection within the international system, analyzing how the formation of a continental economy produces a sort of gravitational effect that favors the formulation of a Chinese international strategy within this conjuncture of systemic transition. We discuss several recurrent analyses of the China's development and international position. Our central arguments is that the development of a continental economy and the widening economic capacity that has accompanied it have become a key instrument of Chinese foreign policy. In other words, China tends to have a strong gravitational effect at the global level which it uses as part of its international strategy. We organize the text in the following manner: first, we discuss the recent evolution of Chinese development, focusing on the challenges of forming an economy of continental dimension; second, we look at how growing Chinese economic abilities imply an increasing gravitational effect on the country at a global level and finally, we argue that Chinese diplomacy uses these prerogatives (economic capacity) to unleash an international strategy that, within this situation of systemic transition, allows the country to widen the scope of its international performance by searching for the routes of lesser resistance.

KEYWORDS: China; Continental Economy; Gravitational Effects. 


\section{L'ECONOMIE CONTINENTALE CHINOISE ET SON EFFET GRAVITATIONNEL}

\section{Diego Pautasso}

L'article aborde le développement national et l'insertion internationale de la Chine. L'objectif, c'est de discuter comment la formation d'une économie continentale en Chine devient un facteur de projection de ce pays dans le système international, en analysant la manière dont la formation d'une économie continentale produit une espèce d'effet gravitationnel qui favorise la formulation de la stratégie internationale chinoise dans cette conjoncture de transition systémique. L'article est développé par la discussion, avec des analyses récurrentes, sur le processus de développement et d'insertion internationale de la Chine. Le principal argument soutenu dans l'article est celui selon lequel, le développement de l'économie continentale et l'agrandissement de la capacité économique, deviennent un instrument de la politique extérieure chinoise. Autrement dit, la Chine tend à créer un fort effet gravitationnel à l'échelle mondiale, et à l'utiliser comme partie de sa stratégie internationale. Voici comment l'article est organisé: dans la première partie, nous examinons l'évolution récente du développement chinois, en soulignant les défis de la formation d'une économie avec des dimensions continentales ; dans la deuxième partie, nous traitons du développement de la capacité chinoise et comment celle-ci implique un effet gravitationnel croissant du pays à l'échelle mondial ; ultimement, nous argumentons que la diplomatie de la Chine utilise ces prérogatives (la capacité économique), pour déclencher une stratégie internationale qui permet au pays, dans ce cadre de transition systémique, d'élargir son espace de performance internationale, en cherchant les lignes de moindre résistance.

MOTS-CLÉS: la Chine ; l'économie continentale ; l'effet gravitationnel. 